\title{
Physical activity ameliorates cardiovascular health in elderly subjects: the functional role of the $\beta$ adrenergic system
}

\author{
Gaetano Santulli ${ }^{1,2,3 *}$, Michele Ciccarelli ${ }^{4}$, Bruno Trimarco ${ }^{2}$ and Guido laccarino ${ }^{4,5}$ \\ 1 Department of Translational Medical Sciences, "Federico II" University, Naples, Italy \\ 2 Department of Advanced Biomedical Sciences, "Federico II" University, Naples, Italy \\ ${ }^{3}$ College of Physicians and Surgeons, New York Presbyterian Hospital, Columbia University in the City of New York, Manhattan, New York, NY, USA \\ ${ }^{4}$ Department of Medicine and Surgery, University of Salerno, Salerno, Italy \\ ${ }^{5}$ Multimedica Research Hospital, Milan, Italy
}

\section{Edited by:}

Dario Leosco, Department of

Translational Medical Sciences-

University Federico II, Italy

Reviewed by:

Wei Ni, Michigan State University, USA

Dario Leosco, Department of Translational Medical Sciences-

University Federico II, Italy

${ }^{*}$ Correspondence:

Gaetano Santulli, College of

Physicians and Surgeons, New York

Presbyterian Hospital, Columbia

University in the City of New York,

Manhattan, New York, NY, USA;

Department of Translational Medical

Sciences and Department of

Advanced Biomedical Sciences,

"Federico II" University, Via Sergio

Pansini, 5, Ed. n. 2, 80131 Naples,

Italy

e-mail: gaetano.santulli@unina.it

\section{INTRODUCTION}

Aging is a multifaceted process characterized by a gradual decline in organ functional reserves (Santulli and Iaccarino, 2013; Trindade et al., 2013). Numerous theories of aging have been proposed hitherto and all of them somehow relate the lifespan of each single species to mechanisms essential for the maintenance of several biological activities (Raj et al., 2012). The free radical theory relates to the failure of defenses against reactive oxygen species (Davis and Williams, 2012; Joiner et al., 2012); the somatic mutation theory relates to an impaired DNA repair (Agronin, 2013); the autoimmune theory proposes that the immune system fails to distinguish self from nonself antigens (Menconi et al., 2008); others relate aging to the loss of epigenetic controls, including but not limited to DNA methylation, or to detrimental effects of toxic chemicals (Sahin et al., 2011; Akbarian et al., 2013; Santulli and Totary-Jain, 2013).

Although the process seems to be continuous and irreversible, aging itself does not mean disease. Indeed, aging is not a pathological condition but an entirely natural phenomenon. Age-linked modifications, however, whose mechanisms have to be looked at the cellular and molecular level, indubitably pave the way for disease (Marks, 2008).

\section{AGING OF CARDIOVASCULAR SYSTEM}

Aging is associated with evident changes in the cardiovascular system that reflect alterations of biochemical adaptive mechanisms (Santulli and Iaccarino, 2013). Normal aging, even in the absence of co-morbidities, results in cardiovascular stiffening (Lakatta, 2003; Santulli, 2012b).

\section{THE HEART}

Significant alterations of measures of ventricular filling and relaxation have been described with aging, including a reversal of the early and late mitral inflow velocities (E/A ratio), a prolongation of isovolumetric relaxation time, a modification of the dynamic longitudinal wall relaxation, and diastolic suction (propagation velocity of early mitral inflow). All these differences have been reported across a wide range of physiological filling pressures (Prasad et al., 2007).

The incidence of left ventricular hypertrophy (LVH), heart failure (HF), and atrial fibrillation (AF) increases dramatically with age (Santulli, 2013). In particular, the prevalence of LVH also increases with rising blood pressure and body mass index (Lanni et al., 2007; Sorriento et al., 2010; de Simone et al., 2013). Crosssectional studies of subjects without hypertension indicate that left ventricular wall thickness increases progressively with age. 
Moreover, in older hospitalized patients without clinically apparent cardiovascular disease, in whom overall cardiac mass was not increased, cardiomyocyte enlargement was observed at autopsy (Olivetti et al., 1995).

The elderly appear to be particularly predisposed to the development of HF. Such a diagnosis is indeed the leading cause of hospitalizations in people $>65$ years of age (Rosca and Hoppel, 2010; Santulli, 2013). In seniors, the underlying substrate for HF, particularly with preserved ejection fraction (occurring in about one-third to one-half of older patients with HF), may in part be the age-associated modification in ventricular compliance and relaxation (Marin-Garcia and Goldenthal, 2008; Oghlakian et al., 2011). Albeit such mechanical changes may not be enough to explain the cause of HF with preserved systolic function by themselves, superimposed conditions including diabetes, coronary disease, or hypertension may tip the scale toward increased filling pressures and pulmonary congestion (Prasad et al., 2007; Ahuja et al., 2013; Hohendanner et al., 2013; Kohlhaas and Maack, 2013). Regular lifelong physical activity preserves cardiac compliance (in the absence of co-morbid conditions) and thereby decreases left ventricular end-diastolic pressure (Prasad et al., 2007).

Lastly, AF is detected in approximately $3-4 \%$ of healthy volunteers over age 60 years without clinical coronary artery disease. Such a rate is 10 -fold higher than in the general adult population (Santulli et al., 2012b). Overall prevalence of AF has been quantified to be $17.8 \%$ in people aged 85 years and above (Santulli, 2013). The lifetime risk to develop AF at the age of 55 years is $23.8 \%$ in men and $22.2 \%$ in women (Boriani et al., 2006; Santulli, 2013). Notably, the development of a rapid irregular pattern of electrical activity, including AF, may have detrimental consequences for hearts that are relatively stiff and relax slowly (D’Ascia et al., 2011; Santulli et al., 2012c; Du et al., 2013; Santulli, 2013).

\section{THE VESSELS}

At the vascular level, cross-sectional studies in humans have shown that wall thickening and dilatation are prominent structural changes that occur within large elastic arteries during aging. The carotid intimal-media thickness increases 2- to 3fold between 20 and 90 years of age (Lakatta, 2003). The aortic wall thickening that occurs with aging consists mainly of intimal thickening (Virmani et al., 1991). Age-associated increase in intimal thickening is accompanied by both luminal dilatation and a reduction in distensibility or compliance, resulting in an increase in vessel stiffness. Pulse wave velocity (PWV), a relatively convenient, non-invasive index of stiffening (Safar et al., 2005), increases with age. Such increase is determined in part by the intrinsic stress/strain relationship (stiffness) of the vascular wall and by the mean arterial pressure. Augmented PWV has traditionally been linked to structural alterations in the media, including increased collagen, reduced elastin content, elastin fractures, and calcification. Prominent age-associated increases in PWV have been demonstrated in populations with little or no atherosclerosis, thus indicating that stiffening can occur independently of atherosclerosis (Boutouyrie et al., 2002). However, more recent data emerging from epidemiological studies indicate that increased large vessel stiffening also occurs in the context of atherosclerosis and diabetes (Milan et al., 2011; Kollias et al., 2012). A potential link might be that stiffness is governed not only by the structural changes within the matrix, as noted above, but also by endothelial regulation of smooth muscle tone and of other aspects of vascular wall structure/function (Costanzo et al., 2010). Of interest, abnormalities of the endothelium have been identified to occur early on in the pathophysiology of atherosclerosis, diabetes, and hypertension (Iaccarino et al., 2004; Santulli et al., 2012a,e).

\section{PHYSICAL ACTIVITY AND CARDIOVASCULAR SYSTEM}

Physical training is associated with improvements in blood pressure regulation, lipid profile, abdominal fat reduction, insulin sensitivity, and hemodynamic, inflammatory and psychosocial parameters (Piepoli et al., 2004; Woodman et al., 2005; Korantzopoulos and Goudevenos, 2007; Niederseer et al., 2007; Werner et al., 2009; Berry et al., 2012). In addition, engaging in physical activity of any intensity (including low-intensity ones) likely positively impacts insulin action and blood glucose control acutely (Colberg, 2012; Santulli et al., 2012e). Aerobic exercise training may significantly lower blood pressure in older hypertensive individuals, improving endothelial function and vascular tone (Hagberg et al., 1989; Dengel et al., 2006). In particular, swimming exercise has been shown to elicit hypotensive effects and improvements in vascular function in previously sedentary older adults (Nualnim et al., 2012). A recent meta-analysis explored the effects of different kinds of physical exercise on blood pressure in adult subjects (Cornelissen and Smart, 2013). Combined training was shown to lower only diastolic blood pressure, whereas endurance, dynamic resistance, and isometric resistance training lowered both systolic and diastolic blood pressure. Isometric resistance training appeared to have the potential for the largest reductions in systolic blood pressure.

\section{EFFECTS OF EXERCISE ON SKELETAL MUSCLE}

Life-long endurance exercise training has been shown to prevent age-associated declines of exercise capacity and cardiac compliance in healthy subjects (Arbab-Zadeh et al., 2004). Moreover, several months to a year of exercise training can increase exercise capacity in healthy subjects (Fujimoto et al., 2010) and HF patients (Sullivan et al., 1988). The improved exercise capacity in HF appears to be related to improvements in peripheral arterial function and skeletal muscle metabolism (Beere et al., 1999). A single bout of strenuous exercise in a previously sedentary subject unleashes a broad array of cellular and molecular processes, which serve to quickly prepare for the next episode of physical exertion. The opposite can also occur quickly, as evidenced by the marked muscle atrophy and decline in exercise performance following forced bed rest in older individuals, which likely mimics the condition resulting from the frequent hospitalizations experienced by older HF patients (Kitzman and Haykowsky, 2012).

\section{WORKLOAD AND CARDIAC PERFORMANCE}

Coats and colleagues proved in a milestone study that homebased physical training programs are feasible even in severe chronic HF and have a beneficial effect on exercise tolerance, peak oxygen consumption, and symptoms (Coats et al., 1990). Indeed, heart rates at submaximal workloads and rate-pressure 
products are significantly reduced by training, and a significant improvement in patient-rated symptom scores has been also reported. Such findings have been confirmed by other investigators (Hambrecht et al., 2000; Kemps et al., 2010), demonstrating that exercise training in patients with stable HF improves the work capacity by enhancing endothelial function and skeletal muscle aerobic metabolism. In addition, physical exercise is associated with reduction of peripheral resistance and results in small but significant improvements in stroke volume and reduction in cardiomegaly. In a very well-designed study Belardinelli and colleagues recently demonstrated that moderate supervised training, at $60 \%$ of peak oxygen consumption $\left(\mathrm{VO}_{2}\right)$, performed twice weekly for 10 years confers a sustained improvement in quality of life compared with non-trained patients (Belardinelli et al., 2012). Such sustained improvements are associated with reduction in major cardiovascular events, including hospitalizations for $\mathrm{HF}$ and cardiac mortality (Belardinelli et al., 2012; Santulli, 2013) and a sustained improvement in quality of life (Khazanie and Granger, 2013). Thus, the commonly held belief that rest is the mainstay of treatment of chronic HF should no longer be accepted.

\section{EXERCISE AND CARDIAC STRUCTURE}

Diastolic dysfunction has been strongly related to decreased exercise capacity in a large population referred for exercise echocardiography and not limited by ischemia, (Grewal et al., 2009). Increased resting and post-exercise left ventricular filling pressures have been also associated with a reduction in exercise capacity. Of note, unlike many other factors that are an inevitable consequence of aging, diastolic dysfunction may be a preventable factor in the development of exercise intolerance. However, it is not completely clear whether alterations in several markers of diastolic function with senescence are a specific manifestation of the aging process or reflect a secondary cardiac adaptation to a more sedentary lifestyle. This issue has been elegantly addressed by Prasad and colleagues, who demonstrated that, in contrast to chamber compliance, age-dependent modifications of ventricular relaxation are only minimally influenced by lifelong endurance training (Prasad et al., 2007). Hence, changes in ventricular compliance with senescence are strongly influenced by physical activity, whereas changes in ventricular relaxation appear to be more likely specific to cardiac senescence and may result from alterations in cardiac regulatory proteins that occur with aging (Loffredo et al., 2013).

\section{PHYSICAL ACTIVITY AND ATRIAL FIBRILLATION}

There are currently controversial results concerning the effect of physical training on AF. In young and middle-aged adults, high-intensity endurance training is associated with higher risk of lone AF (Molina et al., 2008; Mont et al., 2008). On the other hand, a recent report indicated that greater habitual light-tomoderate physical activities are associated with significantly lower risk of new-onset AF in older adults (Mozaffarian et al., 2008). Several factors may explain such apparently divergent findings. $\mathrm{AF}$ is a common clinical manifestation of remarkably heterogeneous cardiac and non-cardiac conditions, including coronary artery disease, valvular disease, hypertension, sleep apnea, alcohol use, pericarditis, hyperthyroidism, and genetic predisposition
(D'Ascia et al., 2011; Santulli and D'Ascia, 2012). Lone AF should exclude subjects with hypertension, clinical or structural cardiopulmonary disease, or age $>60$ years; hence, lone AF explicitly does not exist in older adults (Fuster et al., 2006; Santulli, 2011). Pathophysiology of lone AF, which represents $\leq 10 \%$ of AF cases in the population, may be indeed very different from the much more common AF seen with structural heart disease, hypertension, other disorders, or aging. Thus, physical training could increase incidence of lone AF in young and middle-aged adults but may also attenuate numerous other AF risk factors reducing overall incidence of AF, particularly later in life when risk rises so steeply (Santulli et al., 2012d). Furthermore, activity intensity might modify effects on AF, depending on the balance between acute triggering versus reduction of chronic vulnerability to AF. Then, since nearly 1 in 5 subjects aged $\geq 65$ years are supposed to develop AF during the next 10 years (Mozaffarian et al., 2008), habitual light to moderate physical activity might be an exceptional prescription to help lower such a risk.

\section{AGING, PHYSICAL EXERCISE, AND BETA ADRENERGIC SYSTEM: THE MOLECULAR EVIDENCE CARDIOVASCULAR $\beta$ ADRENERGIC SYSTEM}

Several experimental findings indicate an age-associated decrease in catecholamine-responsiveness in the elderly. In particular, an age-associated decrease in $\beta$ adrenergic receptor $(\beta A R)$ sensitivity and density has been shown in the cardiac muscle and has been mainly attributed to down-regulation and impaired coupling of $\beta A R$ to adenylate cyclase (Lakatta, 2003). The agelinked decline in cardiac $\beta \mathrm{AR}$ response, which is consistent across species, seems to be primarily due to a down-regulation of $\beta_{1} A R s$, as reported in aged explanted human hearts (White et al., 1994). Further, a reduction in the sensitivity of $\beta$ ARs, measured by isoproterenol-induced changes in the catecholamine stimulated adenylate cyclase activity in the myocardium (O'Connor et al., 1981) and in pulse rate and blood pressure (Vestal et al., 1979), had been reported.

Young individuals are more responsive than elderly subjects to isoproterenol-induced increases in blood flow in the brachial artery (van Brummelen et al., 1981). Such features are similar to what seen in patients with HF. Hence, most of the modifications that occur in the sympathetic nervous system with aging (hyposensitivity to adrenergic stress, increased circulating catecholamines and decreased $\beta A R$ responsiveness) are also common in HF patients (Santulli, 2012b).

\section{AGING AND $\beta$ AR SIGNALING ABNORMALITIES}

The age-linked decline in adrenergic responsiveness impairs also vasodilatation, increasing thereby total peripheral resistances (Santulli and Iaccarino, 2013). A generalized impairment of BAR-mediated vasorelaxation has been indeed shown both in human hypertensive patients (Izzo et al., 2008) and in animal models of hypertension (Borkowski et al., 1992; Iaccarino et al., 2004; Santulli et al., 2009). The age-associated decrease in $\beta$ AR-mediated relaxation has been proposed to be due to decreased receptor density, less efficient coupling to adenylate cyclase, impaired generation of cyclic AMP, or attenuated activation of downstream components (Santulli et al., 2013). However, 
there is not a single factor that can entirely explain the age-related deterioration of $\beta$ AR function (Santulli et al., 2011a; Lampri and Elli, 2013). The primary trigger of such homeostatic imbalance seems to be associated with an age-related alteration in the ability of $\beta$ AR to respond to agonists at the cellular level. $\beta$ AR affinity for the ligand is dependent upon its phosphorylation, which in turn is in the domain of $\mathrm{G}$ protein-coupled receptor kinases (GRKs) and GRK2 in particular (Santulli et al., 2011b; Fusco et al., 2012). Intriguingly, both GRK2 expression and activity increase in vascular tissue with aging (Santulli et al., 2013). Furthermore, the transgenic overexpression of GRK2 in the vasculature leads to impaired $\beta A R$ signaling and vasodilatative response, causing a hypertensive phenotype in rodents Such a point of view has been supported in humans by the observation that GRK2 expression correlates with blood pressure as well as impaired $\beta$ AR-mediated adenylate cyclase activity (Sorriento et al., 2012; Santulli et al., 2013). The deterioration in $\beta A R$ function and subsequent cAMP generation (Davinelli et al., 2012) is a common factor underlying hypertension, atherosclerosis, vascular insufficiency, and orthostatic hypotension, all conditions associated to important morbidity and mortality (Santulli, 2012a; Vu et al., 2012).

\section{PHYSICAL EXERCISE AND $\beta$ AR}

The $\beta A R$ system is activated in lymphocytes during prolonged aerobic physical exercise both in healthy subjects and in HF patients (Maki, 1989; Mancini et al., 1989). The number of lymphocyte $\beta A R$ increases after dynamic exercise by a $\beta_{2} A R$ mechanism (Maisel et al., 1990). Such increase can indeed be mimicked by acute administration of exogenous $\beta \mathrm{AR}$ agonists such as isoproterenol and epinephrine but not by norepinephrine (Hazeki, 1973; Deblasi et al., 1986). Moreover, it can be blocked by non-selective $\beta A R$ antagonists such as propranolol and the $\beta_{2} \mathrm{AR}$ selective ICI 118,551 but not by the $\beta_{1}$ AR-selective bisoprolol (Van Tits et al., 1990).

The effects of exercise on cardiovascular catecholamine responsiveness have been extensively studied, pointing out the functional role of $\beta \mathrm{AR}$. An increased responsiveness to isoproterenol has been demonstrated in the myocardium of trained rodents, when compared with sedentary controls (Takeda et al., 1985; Libonati and MacDonnell, 2011). Such responses have been shown to be independent of training-induced alterations in cardiac hypertrophy or hypertrophic marker expression. An

\section{REFERENCES}

Agronin, M. E. (2013). From Cicero to Cohen: developmental theories of aging, from antiquity to the present. Gerontologist. doi: 10.1093/geront/ gnt032. [Epub ahead of print].

Ahuja, P., Wanagat, J., Wang, Z., Wang, Y., Liem, D. A., Ping, P., et al. (2013). Divergent mitochondrial biogenesis responses in human cardiomyopathy. Circulation 127, 1957-1967. doi: 10.1161/CIRCULATIONAHA. 112.001219

Akbarian, S., Beeri, M. S., and Haroutunian, V. (2013). Epigenetic determinants of healthy and

increased sensitivity of $\beta_{2} \mathrm{AR}$ has been indicated as a mechanism underpinning the increased vasodilator response to isoproterenol after exercise (Gaballa et al., 2000; Santulli and Iaccarino, 2013). Several studies have also shown the importance of the $\beta A R$ system in the relaxant response of coronary arteries during exercise. Indeed, the $\beta_{2} \mathrm{AR}$ receptor selective antagonist ICI 118,551 is able to significantly decrease coronary blood flow velocity and increase late diastolic coronary resistance during a running session (DiCarlo et al., 1988; Traverse et al., 1995).

Other recent studies have shown in animal models that physical exercise ameliorates sensitivity of $\beta A R$ when the vasodilator response mediated by such receptors has been previously reduced by the aging process. In particular, a 6-week training program of 5 days/week swimming exercise improved vasodilator response to the non-selective $\beta \mathrm{AR}$ agonist isoproterenol, in coronary arteries, compared with the sedentary group (Santulli and Iaccarino, 2013). Similarly, a 10- to 12 -week treadmill program of 5 days/week running exercise, with 60-min sessions, improved vasodilator response to isoproterenol in gastrocnemius muscle vessels from old rodents, but not in young animals (Donato et al., 2007).

Collectively, the aforementioned studies show the beneficial effects of physical training on vascular sensitivity in the aging process. However, $\beta$ AR responsiveness to exercise is not homogeneous, depending on several factors, including the region of vascular bed to be studied. Indeed, regions of different diameters in the same artery might respond differently to physical exercise. Another noteworthy variable is the type of artery studied: resistance and conductance vessels show indeed different responses.

\section{SUMMARY}

Aging has become one of the most critical issues for industrialized nations, because population average age, and thus the incidence of age-associated disorders, has markedly risen to create a major burden as patients draw heavily on the need for continuing medical treatment and hospital and other community services. In the present review, we examined the relationship between physical training and aging, focusing on the functional role of $\beta$ ARs. The amelioration of $\beta A R$ responsiveness, obtained through means of regular physical training, contributes to the clinical improvement in cardiovascular health reported in elderly subjects.

healthy older men. Circulation 100, 1085-1094. doi: 10.1161/01.CIR. 100.10.1085

Belardinelli, R., Georgiou, D., Cianci, G., and Purcaro, A. (2012). 10-year exercise training in chronic heart failure: a randomized controlled trial. J. Am. Coll. Cardiol. 60, 1521-1528. doi: 10.1016/j.jacc.2012.06.036

Berry, T. R., Chan, C. B., Bell, R. C., and Walker, J. (2012). Collective knowledge: using a consensus conference approach to develop recommendations for physical activity and nutrition programs for persons with type 2 diabetes. Front. Endocrinol. (Lausanne) 3:161. doi: 10.3389/fendo.2012. 00161

Boriani, G., Diemberger, I., Martignani, C., Biffi, M., and Branzi, A. (2006). The epidemiological burden of atrial fibrillation: a challenge for clinicians and health care systems. Eur. Heart J. 27, 893-894. doi: 10.1093/eurheartj/ehi651

Borkowski, K. R., Gros, R., and Schneider, H. (1992). Vascular betaadrenoceptor-mediated responses in hypertension and ageing in rats. J. Auton. Pharmacol. 12, 389-401. 
doi: $\quad 10.1111 / j .1474-8673.1992$. tb00387.x

Boutouyrie, P., Tropeano, A. I., Asmar, R., Gautier, I., Benetos, A., Lacolley, P., et al. (2002). Aortic stiffness is an independent predictor of primary coronary events in hypertensive patients: a longitudinal study. Hypertension 39, 10-15. doi: 10.1161/hy0102.099031

Coats, A. J., Adamopoulos, S., Meyer, T. E., Conway, J., and Sleight, P. (1990). Effects of physical training in chronic heart failure. Lancet 335, 63-66. doi: 10.1016/0140-6736(90)90536-E

Colberg, S. R. (2012). Physical activity: the forgotten tool for type 2 diabetes management. Front. Endocrinol. (Lausanne) 3:70. doi: 10.3389/fendo.2012.00070

Cornelissen, V. A., and Smart, N. A. (2013). Exercise training for blood pressure: a systematic review and meta-analysis. J. Am. Heart Assoc. 2:e004473. doi: 10.1161/JAHA.112.004473

Costanzo, P., Perrone-Filardi, P., Vassallo, E., Paolillo, S., Cesarano, P., Brevetti, G., et al. (2010). Does carotid intima-media thickness regression predict reduction of cardiovascular events? A meta-analysis of 41 randomized trials. J. Am. Coll. Cardiol. 56, 2006-2020. doi: 10.1016/j.jacc.2010.05.059

D’Ascia, S. L., D’Ascia, C., Marino, V., Lombardi, A., Santulli, R., Chiariello, M., et al. (2011). Cardiac resynchronisation therapy response predicts occurrence of atrial fibrillation in non-ischaemic dilated cardiomyopathy. Int. J. Clin. Pract. 65, 1149-1155. doi: 10.1111/j.1742-1241.2011.02732.x

Davinelli, S., Willcox, D. C., and Scapagnini, G. (2012). Extending healthy ageing: nutrient sensitive pathway and centenarian population. Immun. Ageing 9, 9. doi: 10.1186/1742-4933-9-9

Davis, R. E., and Williams, M. (2012). Mitochondrial function and dysfunction: an update. J. Pharmacol. Exp. Ther. 342, 598-607. doi: 10.1124/jpet.112.192104

Deblasi, A., Maisel, A. S., Feldman, R. D., Ziegler, M. G., Fratelli, M., Dilallo, M., et al. (1986). In vivo regulation of beta-adrenergic receptors on human mononuclear leukocytes: assessment of receptor number, location, and function after posture change, exercise, and isoproterenol infusion. J. Clin. Endocrinol. Metab. 63, 847-853. doi: 10.1210/jcem-634-847

Dengel, D. R., Brown, M. D., Reynolds, T. H., Kuskowski, M. A., and
Supiano, M. A. (2006). Effect of aerobic exercise training on blood pressure sensitivity to dietary sodium in older hypertensives. J. Hum. Hypertens. 20, 372-378. doi: 10.1038/sj.jhh.1001989

de Simone, G., Devereux, R. B., Izzo, R., Girfoglio, D., Lee, E. T., Howard, B. V., et al. (2013). Lack of reduction of left ventricular mass in treated hypertension: the strong heart study. J. Am. Heart Assoc. 2:e000144. doi: 10.1161/JAHA.113. 000144

DiCarlo, S. E., Blair, R. W., Bishop, V. S., and Stone, H. L. (1988). Role of beta 2 -adrenergic receptors on coronary resistance during exercise. J. Appl. Physiol. 64, 2287-2293.

Donato, A. J., Lesniewski, L. A., and Delp, M. D. (2007). Ageing and exercise training alter adrenergic vasomotor responses of rat skeletal muscle arterioles. J. Physiol. 579, 115-125. doi: 10.1113/jphysiol.2006.120055

Du, H., Fan, J., Ling, Z., Woo, K., Su, L., Chen, S., et al. (2013). Effect of nifedipine versus telmisartan on prevention of atrial fibrillation recurrence in hypertensive patients. Hypertension 61, 786-792. doi: 10.1161/HYPERTEN SIONAHA.111.202309

Fujimoto, N., Prasad, A., Hastings, J. L., Arbab-Zadeh, A., Bhella, P. S., Shibata, S., et al. (2010). Cardiovascular effects of 1 year of progressive and vigorous exercise training in previously sedentary individuals older than 65 years of age. Circulation 122, 1797-1805. doi: 10.1161/CIRCULATIONAHA. 110.973784

Fusco, A., Santulli, G., Sorriento, D., Cipolletta, E., Garbi, C., Dorn, G. W. 2nd., et al. (2012). Mitochondrial localization unveils a novel role for GRK2 in organelle biogenesis. Cell. Signal. 24, 468-475. doi: 10.1016/j.cellsig.2011.09.026

Fuster, V., Ryden, L. E., Cannom, D. S., Crijns, H. J., Curtis, A. B., Ellenbogen, K. A., et al. (2006). ACC/AHA/ESC 2006 Guidelines for the management of patients with atrial fibrillation: a report of the American college of cardiology/American heart association task force on practice guidelines and the european society of cardiology committee for practice guidelines (Writing committee to revise the 2001 guidelines for the management of patients with atrial fibrillation): developed in collaboration with the European heart rhythm association and the heart rhythm society. Circulation
114, e257-e354. doi: 10.1161/ CIRCULATIONAHA.106.177292

Gaballa, M. A., Eckhart, A. D., Koch, W. J., and Goldman, S. (2000). Vascular beta-adrenergic receptor adenylyl cyclase system in maturation and aging. J. Mol. Cell. Cardiol. 32, 1745-1755. doi: 10.1006/jmcc.2000.1210

Grewal, J., McCully, R. B., Kane, G. C., Lam, C., and Pellikka, P. A. (2009). Left ventricular function and exercise capacity. JAMA 301, 286-294. doi: 10.1001/jama.2008.1022

Hagberg, J. M., Montain, S. J., Martin, W. H. 3rd., and Ehsani, A. A. (1989). Effect of exercise training in 60- to 69-year-old persons with essential hypertension. Am. J. Cardiol. 64, 348-353. doi: 10.1016/00029149(89)90533-X

Hambrecht, R., Gielen, S., Linke, A., Fiehn, E., Yu, J., Walther, C., et al. (2000). Effects of exercise training on left ventricular function and peripheral resistance in patients with chronic heart failure: a randomized trial. JAMA 283, 3095-3101. doi: 10.1001/jama.283.23.3095

Hazeki, T. (1973). Hemodynamic and metabolic effects of activities of the adrenergic beta receptor in physical exercise. Jpn. Circ. J. 37, 141-161. doi: 10.1253/jcj.37.141

Hohendanner, F., Ljubojevic, S., Macquaide, N., Sacherer, M., Sedej, S., Biesmans, L., et al. (2013). Intracellular dyssynchrony of diastolic cytosolic $[\mathrm{Ca} 2+]$ decay in ventricular cardiomyocytes in cardiac remodeling and human heart failure. Circ. Res. doi: 10.1161/ CIRCRESAHA.113.300895. [Epub ahead of print].

Iaccarino, G., Ciccarelli, M., Sorriento, D., Cipolletta, E., Cerullo, V., Iovino, G. L., et al. (2004). AKT participates in endothelial dysfunction in hypertension. Circulation 109, 2587-2593. doi: 10.1161/01. CIR.0000129768.35536.FA

Izzo, R., Cipolletta, E., Ciccarelli, M., Campanile, A., Santulli, G., Palumbo, G., et al. (2008). Enhanced GRK2 expression and desensitization of betaAR vasodilatation in hypertensive patients. Clin. Transl. Sci. 1, 215-220. doi: 10.1111/j.1752-8062.2008.00050.x

Joiner, M. L., Koval, O. M., Li, J., He, B. J., Allamargot, C., Gao, Z., et al. (2012). CaMKII determines mitochondrial stress responses in heart. Nature 491, 269-273. doi: 10.1038/nature11444

Kemps, H. M., de Vries, W. R., Schmikli, S. L., Zonderland, M. L., Hoogeveen, A. R., Thijssen,
E. J., et al. (2010). Assessment of the effects of physical training in patients with chronic heart failure: the utility of effortindependent exercise variables. Eur. J. Appl. Physiol. 108, 469-476. doi: 10.1007/s00421-009-1230-3

Khazanie, P., and Granger, C. B. (2013). ACP Journal Club. A 10-year exercise program improved oxygen consumption and quality of life in stable chronic heart failure. Ann. Intern. Med. 158, JC6. doi: 10.7326/00034819-158-4-201302190-02006

Kitzman, D. W., and Haykowsky, M. J. (2012). Invited editorial commentary for American heart journal mechanisms of exercise training in heart failure with preserved ejection fraction: central disappointment and peripheral promise. Am. Heart J. 164, 807-809. doi: 10.1016/j.ahj.2012.09.002

Kohlhaas, M., and Maack, C. (2013). Calcium release microdomains and mitochondria. Cardiovasc. Res. 98, 259-268. doi: 10.1093/cvr/cvt032

Kollias, A., Stergiou, G. S., Dolan, E., and O'Brien, E. (2012). Ambulatory arterial stiffness index: a systematic review and meta-analysis. Atherosclerosis 224, 291-301. doi: $\quad 10.1016 /$ j.atherosclerosis. 2012.03.039

Korantzopoulos, P., and Goudevenos, J. A. (2007). The failing heart. N. Engl. J. Med. 356, 2545.

Lakatta, E. G. (2003). Arterial and cardiac aging: major shareholders in cardiovascular disease enterprises: part III: cellular and molecular clues to heart and arterial aging. Circulation 107, 490-497. doi: 10.1161/01.CIR.0000048894. 99865.02

Lampri, E., and Elli, I. (2013). "Angiogenesis: something old, something new," in Angiogenesis: Insights from a Systematic Overview, ed G. Santulli (New York, NY: Nova Science Publishers, Inc.), 1-30.

Lanni, F., Santulli, G., Izzo, R., Rubattu, S., Zanda, B., Volpe, M., et al. (2007). The Pl(A1/A2) polymorphism of glycoprotein IIIa and cerebrovascular events in hypertension: increased risk of ischemic stroke in high-risk patients. J. Hypertens. 25, 551-556. doi: 10.1097/HJH.0b013e328013cd67

Libonati, J. R., and MacDonnell, S. M. (2011). Cardiac betaadrenergic responsiveness with exercise. Eur. J. Appl. Physiol. 111, 2735-2741. doi: 10.1007/s00421011-1909-0

Loffredo, F. S., Steinhauser, M. L., Jay, S. M., Gannon, J., Pancoast, J. R., Yalamanchi, P., et al. (2013). 
Growth differentiation factor 11 is a circulating factor that reverses age-related cardiac hypertrophy. Cell 153, 828-839. doi: 10.1016/j.cell.2013.04.015

Maisel, A. S., Harris, T., Rearden, C. A., and Michel, M. C. (1990). Beta-adrenergic receptors in lymphocyte subsets after exercise. Alterations in normal individuals and patients with congestive heart failure. Circulation 82, 2003-2010. doi: 10.1161/01.CIR.82.6.2003

Maki, T. (1989). Density and functioning of human lymphocytic beta-adrenergic receptors during prolonged physical exercise. Acta Physiol. Scand. 136, 569-574. doi: 10.1111/j.17481716.1989.tb08703.x

Mancini, D. M., Frey, M. J., Fischberg, D., Molinoff, P. B., and Wilson, J. R. (1989). Characterization of lymphocyte beta-adrenergic receptors at rest and during exercise in ambulatory patients with chronic congestive heart failure. Am. J. Cardiol. 63, 307-312. doi: 10.1016/00029149(89)90336-6

Marin-Garcia, J., and Goldenthal, M. J. (2008). Mitochondrial centrality in heart failure. Heart Fail. Rev. 13, 137-150. doi: 10.1007/s10741-0079079-1

Marks, A. R. (2008). Physiological systems under pressure. J. Clin. Invest. 118, 411-412. doi: 10.1172/JCI34756

Menconi, F., Monti, M. C., Greenberg, D. A., Oashi, T., Osman, R., Davies, T. F., et al. (2008). Molecular amino acid signatures in the MHC class II peptide-binding pocket predispose to autoimmune thyroiditis in humans and in mice. Proc. Natl. Acad. Sci. U.S.A. 105, 14034-14039. doi: 10.1073/pnas. 0806584105

Milan, A., Tosello, F., Fabbri, A., Vairo, A., Leone, D., Chiarlo, M., et al. (2011). Arterial stiffness: from physiology to clinical implications. High Blood Press. Cardiovasc. Prev. 18, 1-12. doi: 10.2165/11588020000000000-00000

Molina, L., Mont, L., Marrugat, J., Berruezo, A., Brugada, J., Bruguera, J., et al. (2008). Long-term endurance sport practice increases the incidence of lone atrial fibrillation in men: a follow-up study. Europace 10, 618-623. doi: 10.1093/ europace/eun071

Mont, L., Tamborero, D., Elosua, R., Molina, I., Coll-Vinent, B., Sitges, M., et al. (2008). Physical activity, height, and left atrial size are independent risk factors for lone atrial fibrillation in middle-aged healthy individuals. Europace 10, 15-20. doi: 10.1093/europace/eum263

Mozaffarian, D., Furberg, C. D., Psaty, B. M., and Siscovick, D. (2008). Physical activity and incidence of atrial fibrillation in older adults: the cardiovascular health study. Circulation 118, 800-807. doi: 10.1161/CIRCULATIONAHA.108. 785626

Niederseer, D., Thaler, C., and Niebauer, J. (2007). The failing heart. N. Engl. J. Med. 356, 2545.

Nualnim, N., Parkhurst, K., Dhindsa, M., Tarumi, T., Vavrek, J., and Tanaka, H. (2012). Effects of swimming training on blood pressure and vascular function in adults $>50$ years of age. Am. J. Cardiol. 109, 1005-1010. doi: 10.1016/j.amjcard.2011.11.029

O'Connor, S. W., Scarpace, P. J., and Abrass, I. B. (1981). Age-associated decrease of adenylate cyclase activity in rat myocardium. Mech. Ageing Dev. 16, 91-95. doi: 10.1016/00476374(81)90036-1

Oghlakian, G. O., Sipahi, I., and Fang, J. C. (2011). Treatment of heart failure with preserved ejection fraction: have we been pursuing the wrong paradigm? Mayo Clin. Proc. 86, 531-539. doi: 10.4065/mcp.2010.0841

Olivetti, G., Giordano, G., Corradi, D., Melissari, M., Lagrasta, C., Gambert, S. R., et al. (1995). Gender differences and aging: effects on the human heart. J. Am. Coll. Cardiol. 26, 1068-1079. doi: 10.1016/07351097(95)00282-8

Piepoli, M. F., Davos, C., Francis, D. P., Coats, A. J., and Extra, M. C. (2004). Exercise training meta-analysis of trials in patients with chronic heart failure (ExTraMATCH). BMJ 328, 189. doi: 10.1136/bmj.328.7441.711-b

Prasad, A., Popovic, Z. B., ArbabZadeh, A., Fu, Q., Palmer, D., Dijk, E., et al. (2007). The effects of aging and physical activity on Doppler measures of diastolic function. Am. J. Cardiol. 99, 1629-1636. doi: 10.1016/j.amjcard.2007.01.050

Raj, K., Chanu, S. I., and Sarkar, S. (2012). Decoding Complexity of Aging. Cell Dev. Biol. 1:e117. doi: 10.4172/2168-9296.1000e117

Rosca, M. G., and Hoppel, C. L. (2010). Mitochondria in heart failure. Cardiovasc. Res. 88, 40-50. doi: $10.1093 / \mathrm{cvr} / \mathrm{cvq} 240$

Safar, M. E., Cattan, V., Lacolley, P., Nzietchueng, R., Labat, C., Lajemi, M., et al. (2005). Aldosterone synthase gene polymorphism, stroke volume and age-related changes in aortic pulse wave velocity in subjects with hypertension. J. Hypertens. 23, 1159-1166. doi: 10.1097/01.hjh. 0000170378.08214 .13

Sahin, E., Colla, S., Liesa, M., Moslehi, J., Muller, F. L., Guo, M., et al. (2011). Telomere dysfunction induces metabolic and mitochondrial compromise. Nature 470, 359-365. doi: 10.1038/nature09787

Santulli, G. (2011). "Classification of syncope-producing cardiac arrhythmias," in Comas and Syncope: Causes, Prevention and Treatment, eds E. Silva and G. Cruz (New York, NY: Nova Science Publishers, Inc.), 166-177.

Santulli, G. (2012a). Coronary heart disease risk factors and mortality. JAMA 307, 1137. doi: 10.1001/jama.2012.323

Santulli, G. (2012b). Thrombolysis outcomes in acute ischemic stroke patients with prior stroke and diabetes mellitus. Neurology 78, 840. doi: 10.1212/WNL.0b013e31824de51b

Santulli, G. (2013). Epidemiology of cardiovascular disease in the $21 \mathrm{st}$ century: updated numbers and updated facts J. Cardiovasc. Dis. (JCvD) 1, 1-2.

Santulli, G., Basilicata, M. F., De Simone, M., Del Giudice, C., Anastasio, A., Sorriento, D., et al. (2011a). Evaluation of the anti-angiogenic properties of the new selective alphaVbeta3 integrin antagonist RGDechiHCit. J. Transl. Med. 9, 7. doi: 10.1186/1479-5876-9-7

Santulli, G., Campanile, A., Spinelli, L., Assante di Panzillo, E., Ciccarelli, M., Trimarco, B., et al. (2011b). G protein-coupled receptor kinase 2 in patients with acute myocardial infarction. Am. J. Cardiol. 107, 1125-1130. doi: 10.1016/j.amjcard.2010.12.006

Santulli, G., Ciccarelli, M., Palumbo, G., Campanile, A., Galasso, G., Ziaco, B., et al. (2009). In vivo properties of the proangiogenic peptide QK. J. Transl. Med. 7, 41. doi: 10.1186/1479-5876-7-41

Santulli, G., Cipolletta, E., Sorriento, D., Del Giudice, C., Anastasio, A., Monaco, S., et al. (2012a). CaMK4 gene deletion induces hypertension. J. Am. Heart Assoc. 1, e001081. doi: 10.1161/JAHA.112.001081

Santulli, G., D'Ascia, S., and D'Ascia, C. (2012b). Regarding the impact of left ventricular size on response to cardiac resynchronization therapy. Am. Heart J. 163, el1. doi: 10.1016/j.ahj.2012.01.001

Santulli, G., D'Ascia, S. L., and D'Ascia, C. (2012c). Development of atrial fibrillation in recipients of cardiac resynchronization therapy: the role of atrial reverse remodelling. Can. J. Cardiol. 28, 245 e217.

Santulli, G., D'Ascia, S., Marino, V., and D'Ascia, C. (2012d). Atrial function in patients undergoing CRT. JACC Cardiovasc. Imaging 5, 124-125. doi: 10.1016/j.jcmg.2011.11.002

Santulli, G., Lombardi, A., Sorriento, D., Anastasio, A., Del Giudice, C., Formisano, P., et al. (2012e). Age-related impairment in insulin release: the essential role of beta(2)adrenergic receptor. Diabetes 61, 692-701. doi: 10.2337/db11-1027

Santulli, G., and D'Ascia, C. (2012). Atrial remodelling in echocardiographic super-responders to cardiac resynchronization therapy. Heart 98, 517. doi: 10.1136/heartjnl-2012-301731

Santulli, G., and Iaccarino, G. (2013). Pinpointing beta adrenergic receptor in ageing pathophysiology: victim or executioner? Evidence from crime scenes. Immun. Ageing 10, 10. doi: 10.1186/17424933-10-10

Santulli, G., and Totary-Jain, H. (2013). Tailoring mTOR-based therapy: molecular evidence and clinical challenges. Pharmacogenomics. (in press).

Santulli, G., Trimarco, B., and Iaccarino, G. (2013). G-proteincoupled receptor kinase 2 and hypertension: molecular insights and pathophysiological mechanisms. High Blood Press. Cardiovasc. Prev. 20, 5-12. doi: 10.1007/s40292013-0001-8

Sorriento, D., Santulli, G., Del Giudice, C., Anastasio, A., Trimarco, B., and Iaccarino, G. (2012). Endothelial cells are able to synthesize and release catecholamines both in vitro and in vivo. Hypertension 60, 129-136. doi: 10.1161/ HYPERTENSIONAHA.111.189605

Sorriento, D., Santulli, G., Fusco, A., Anastasio, A., Trimarco, B., and Iaccarino, G. (2010). Intracardiac injection of AdGRK5-NT reduces left ventricular hypertrophy by inhibiting NF-kappaB-dependent hypertrophic gene expression. Hypertension 56, 696-704. doi: $10.1161 /$ HYPERTENSIO NAHA.110.155960

Sullivan, M. J., Higginbotham, M. B., and Cobb, F. R. (1988). Exercise training in patients with severe left ventricular dysfunction. Hemodynamic and metabolic effects. Circulation 78, 506-515. doi: 10.1161/01. CIR.78.3.506

Takeda, N., Dominiak, P., Turck, D., Rupp, H., and Jacob, R. (1985). The 
influence of endurance training on mechanical catecholamine responsiveness, beta-adrenoceptor density and myosin isoenzyme pattern of rat ventricular myocardium. Basic Res. Cardiol. 80, 88-99. doi: 10.1007/BF01906747

Traverse, J. H., Altman, J. D., Kinn, J., Duncker, D. J., and Bache, R. J. (1995). Effect of beta-adrenergic receptor blockade on blood flow to collateral-dependent myocardium during exercise. Circulation 91, 1560-1567. doi: 10.1161/01.CIR.91.5.1560

Trindade, L. S., Aigaki, T., Peixoto, A. A., Balduino, A., Manica da Cruz, I. B., and Heddle, J. G. (2013). A novel classification system for evolutionary aging theories. Front. Genet. 4:25. doi: 10.3389/fgene.2013.00025 van Brummelen, P., Buhler, F. R., Kiowski, W., and Amann, F. W. (1981). Age-related decrease in cardiac and peripheral vascular responsiveness to isoprenaline: studies in normal subjects. Clin. Sci. (Lond.) 60, 571-577.

Van Tits, L. J., Michel, M. C., Grosse-Wilde, H., Happel,
M., Eigler, F. W., Soliman, A., et al. (1990). Catecholamines increase lymphocyte beta 2adrenergic receptors via a beta 2-adrenergic, spleen-dependent process. Am. J. Physiol. 258, E191-E202.

Vestal, R. E., Wood, A. J., and Shand, D. G. (1979). Reduced betaadrenoceptor sensitivity in the elderly. Clin. Pharmacol. Ther. 26, 181-186.

Virmani, R., Avolio, A. P., Mergner, W. J., Robinowitz, M., Herderick, E. E., Cornhill, J. F., et al. (1991). Effect of aging on aortic morphology in populations with high and low prevalence of hypertension and atherosclerosis. Comparison between occidental and Chinese communities. Am. J. Pathol. 139, 1119-1129.

Vu, T. H., Stamler, J., Liu, K., Mcdermott, M. M., Lloyd-Jones, D. M., Pirzada, A., et al. (2012). Prospective relationship of low cardiovascular risk factor profile at younger ages to ankle-brachial index: 39-year follow-up-the chicago healthy aging study. J. Am.
Heart Assoc. 1, e001545. doi: 10.1161/JAHA.112.001545

Werner, C., Furster, T., Widmann, T., Poss, J., Roggia, C., Hanhoun, M., et al. (2009). Physical exercise prevents cellular senescence in circulating leukocytes and in the vessel wall. Circulation 120, 2438-2447. doi: 10.1161/CIRCULATIONAHA. 109.861005

White, M., Roden, R., Minobe, W., Khan, M. F., Larrabee, P. Wollmering, M., et al. (1994). Agerelated changes in beta-adrenergic neuroeffector systems in the human heart. Circulation 90, 1225-1238. doi: 10.1161/01.CIR.90.3.1225

Woodman, C. R., Thompson, M. A., Turk, J. R., and Laughlin, M. H. (2005). Endurance exercise training improves endotheliumdependent relaxation in brachial arteries from hypercholesterolemic male pigs. J. Appl. Physiol. 99, 1412-1421. doi: 10.1152/ japplphysiol.00293.2005

Conflict of Interest Statement: The authors declare that the research was conducted in the absence of any commercial or financial relationships that could be construed as a potential conflict of interest.

Received: 30 June 2013; paper pending published: 22 July 2013; accepted: 23 July 2013; published online: 12 August 2013.

Citation: Santulli G, Ciccarelli $M$ Trimarco B and Iaccarino $G$ (2013) Physical activity ameliorates cardiovascular health in elderly subjects: the functional role of the $\beta$ adrenergic system. Front. Physiol. 4:209. doi: 10.3389/ fphys.2013.00209

This article was submitted to Frontiers in Vascular Physiology, a specialty of Frontiers in Physiology.

Copyright (c) 2013 Santulli, Ciccarelli, Trimarco and Iaccarino. This is an openaccess article distributed under the terms of the Creative Commons Attribution License (CC BY). The use, distribution or reproduction in other forums is permitted, provided the original author(s) or licensor are credited and that the original publication in this journal is cited, in accordance with accepted academic practice. No use, distribution or reproduction is permitted which does not comply with these terms. 